\title{
ABSTRACTS
}

\section{Law and Development in Change}

\author{
By Franz von Benda-Beckmann, Halle-Wittenberg
}

All over the world governments have used law to organise and legitimate social, economic and political change, or to prevent change. All such "legal engineering" efforts are influenced and filtered through the social organisation they intend to change, and also by the legal structures of this organisation. The legal dimension of social organisation in many societies is further complicated by the fact of the coexistence of more than one, often contradictory legal orders - a situation usually referred to as "legal pluralism". But while political authorities all over the world have engaged in legal engineering, the issue of law as a factor in development has for long periods been neglected in the realm of development policies and discourses. It was considered to be of secondary importance compared with technological and economic changes. Research on the introduction of law into local settings characterized by legal pluralism was even less treated as useful knowledge that could inform development theory and practice. During the past two decades, however, law has been given increasing attention in development planning and practice. This contribution places this renaissance of law and the emerging acknowledgement of legal pluralism in development policy into a historical context. It then discusses the complexity of legal pluralism and what "taking legal pluralism into account" by development agents means. It concludes with an analysis of the frequently uneasy relationship between policy makers and research oriented academics.

\section{Law and development in law school: Scope and didactics of an intra- and interdisciplinary subject}

By Michael Riegner, Passau and Philipp Dann, Heidelberg

This contribution argues for the introduction of „law and development“ as a course at German law schools. It holds that the study of law and development would offer important insights from a substantive as well as methodological perspective, as it touches one of the central problems the world faces today and underlines how law is linked to several other disciplines, which would have to be reflected in the way this course is taught. Teaching law and development based on that understanding would, last but not least, liven up the didactics of German law school teaching in general. To make the case, we sketch out how a course on law and development could be structured, thus describing the substantive contours of the field. In a second step, we describe which didactics should be deployed to teach law and development - and how it might modernize German law school teaching 
without ignoring the all-important limits of what is relevant for the First State Examination. In fact we argue that teaching law and development makes for better law students - when it comes to black letter law, the law in action and life.

\title{
The role of developing countries in the WTO
}

\author{
By Silke Steiner, Wien
}

When the GATT entered into force as a provisional agreement in 1948, it did not contain any provisions taking into account the special situation of developing countries. However, in the course of the years a number of provisions foreseeing the possibility of a "special and differential treatment" (SDT) of developing countries were included into the GATT and later into the legal framework of the newly founded WTO. Especially the so-called "Enabling Clause", which was adopted at the end of the Tokyo Round in 1979, represented a significant step in that respect.

In addition, examples like the concept of conditionality, which underpins not only the Generalized System of Preferences established by the EC but also the EC's contractual relations to the ACP countries in general, illustrate that the interdependence between trade and law and development is by far going beyond the institutional and legal framework of the WTO.

Although looking nice on the paper, in practice many of the provisions guaranteeing a special and differential treatment of developing countries did not prove to be very successful. One main reason for the often lacking efficiency of many of those provisions can be seen in their non-coercive nature. Moreover, developing countries usually do not have enough economic and political power to make effectively use of their rights. As development has been declared one of the major issues of the Doha Development Round, a progress in the currently stagnant negotiations would be highly desirable from the developing countries' point of view.

\section{Water at a Price, Time Squandered: The Privatization of Water Supply as Failed Developmental Ideology}

\section{By Petra Dobner, Berlin/Halle}

Since the beginning of the 1990s private participation in public decision-making and privatization of services has increasingly been understood as a necessity in order to enhance efficiency in reaching public goods in developing countries. In the face of severe public deficiencies in providing sufficient sanitary infrastructure and access to fresh water for everybody this general trend was also echoed in a call for increasing privatization of water services. Opposition, though, was strong from the beginning, and the claim of a "human right to water" was expressed against what was understood as a capitalist onset on the 
world's last public resource. This article critically reviews the debate and its outcomes. It contrasts the arguments which were exchanged by supporters and opponents and presents the factual results of the privatization agenda. The alarming result is that neither side was verified, leaving the urging question of how to provide existential water services to the poor as open as it was before.

\section{Caught between two worlds: Experiences of western retail companies with social clauses in global sourcing markets}

By Jochen Jütte-Overmeyer, Düsseldorf

The article describes the political and legal environment and the current discussion regarding Corporate Social Responsibility (CSR) with particular reference to Western retail companies. It is discussed that CSR tools, if seriously implemented in the own management procedures, have become an indispensable strategy for companies to achieve sustainability and risk limitation. Especially in textile trade, an industry which had gone global already a long time ago, the challenges of worldwide monitoring down the long textile chain have become the main criteria for successfully implementing CSR. It is shown that private law fills the gap in an effective execution of international treaties and norms on the national level, which state actors alone are often unable to achieve. Driven by the power of markets, global human and social rights have become part of the business agenda and are implemented in international purchase contracts. The issue is still as topical as ever, as civil society, widely represented by NGOs, shifts responsibilities for the whole supply chain and far beyond legal restraints more and more towards the trading and retail companies. While pressure has been applied by campaigning for a long time, there are now new developments with a view to create national legislation holding companies legally liable for their whole supply chain.

Finally the author refers to possibilities and experiences, especially for retail companies, to organize their individual implementation of a convincing and efficient CSR policy including the introduction of monitoring and development tools.

\section{Cambodia and the fight for law: A case study in law and development}

\section{By Joerg Menzel, Phnom Penh}

Cambodia is a natural test case for any "law and development" concept. Cambodia probably was the most lawless country in the $20^{\text {th }}$ century during the regime of the infamous Khmer Rouge between 1975 and 1979. Cambodia was not a failed state during that time, as it had functioning power structures and a government in control, but it was a state without any modern legal structures. There was no lawmaking and there was nothing even close to courts. Law was not high on the agenda during the communist regime between 1979 and 
1989, but has become an important reform agenda ever since. In 1993 a liberal and democratic constitution was adopted. Many laws have been adopted since the late 1980s, particularly in recent years, but there are still loopholes and the quality of legislation still often lacks international standards. The judicial system is still considered to be flawed, characterized by incompetence, corruption and political interferences. A system of legal education has been re-established step by step, but is still struggling for quality, not to mention the lack of a culture of legal science.

The reintroduction of an appropriate legal system in Cambodia is part of the extensive development-cooperation in the country. Bilateral partners and international organizations and pressure and help Cambodia in this process, sometimes fighting with each other not only about concepts, but also for influence. France and Japan have recently been major partners, preparing codes in the fields of criminal and private law. Other partners are also active, Germany among them. They all struggle with a government, which seem not always up to its own words, when it comes to hard reform of the court system or overcoming corruption. The donors' approaches themselves need some critical reconsideration, however, not with the conclusion that it would be better to drop out, but to improve strategies and make help more effective, as next generation's Cambodia deserves to live under an improved rule of law. 